\title{
Fragmentation Without Cleavages? Endogenous Fractionalization in the Brazilian Party System
}

\author{
Cesar Zucco Jr. and Timothy J. Power \\ forthcoming in Comparative Politics (ISSN 0010-4159) \\ accepted for publication on 27 August 2019 \\ print version tentatively scheduled for publication in vol. 53, issue 3 (April 2021)
}

\begin{abstract}
This article investigates the causes of party system hyperfragmentation in Brazil. We ask why hyperfragmentation - understood as extreme multipartism that continues to fractionalize - occurs despite significant changes to social cleavages or to electoral rules. Using survey data from federal legislators, we rule out the possibility of new issue-based multidimensionality. Using new estimates of the ideological position of legislative parties, we show that new party entry was not driven by polarization or convergence among traditional parties. We advance an alternative explanation of "fragmentation without cleavages," arguing that changing dynamics of electoral list composition, federal party funding, and coalition management have changed the context of political ambition. For strategically minded elites, it is more attractive than ever before to be a dominant player in a small party.
\end{abstract}

What explains the continued fractionalization of an already highly fragmented party system? As soon as Brazil transitioned to democracy in the mid-1980s, the country was cited as a case of extreme multipartism. Yet few then imagined how much party fragmentation would continue to rise. Brazil now boasts the highest effective number of parliamentary parties (ENPP) ever recorded in the democratic world, by a wide margin. It was 13.23 following the 2014 congressional elections, and ballooned to a jaw-dropping 16.46 in 2018. Even more striking, parliamentary fragmentation skyrocketed during a long period of stable presidential competition (1994-2014) in which two parties, the PT and PSDB, enjoyed a virtual duopoly in presidential elections. ${ }^{1}$ In the same sense that inflation can spiral into hyperinflation, postauthoritarian Brazil appears as an unusual case in which high fractionalization generated even higher fractionalization, in a process that we refer to as hyperfragmentation. 
Why did this fragmentation fail to plateau? The canonical model in comparative politics is that a mix of underlying cleavages, whether identity related (e.g., ethnic, racial, linguistic, religious, regional, or class-based) or issue related (redistribution, state intervention in the economy, values), combine with discrete institutional incentives, mainly deriving from electoral formulae, in order to shape the resulting ENPP. ${ }^{2}$ Coppedge noted that the main institutional driver of ENPP is district magnitude, but argued that "the underlying patterns of politicization in society" were a stronger predictor of the number of parties in any given polity. ${ }^{3}$ He predicted that absent a strong shock, the number of parties should converge to a country-specific long-term average after a few elections.

There is ample evidence that Brazil possesses extremely permissive electoral rules, ${ }^{4}$ but most of these (notably district magnitude) have not changed substantially over time. Hence, the number of parties "should have" stabilized, unless changing cleavage structures somehow created the opportunity for, or necessity of, more parties. Yet there is considerable evidence that identity-based cleavages are not overtly salient in Brazil; that is, even though the country is regionally and racially heterogeneous, subnational origin and skin color are only weakly politicized at best. ${ }^{5}$ With both the main electoral rules broadly stable and the main conventional social cleavages insufficiently politicized, we have to rule them out as potential causes for hyperfragmentation.

Leaving institutional design and social structure aside, we can turn to politics and public policy. Could it be that the proliferation of political parties is at all related to complex combinations of issue-based coalitions? In this article, we address this question by probing systemic characteristics of Brazilian party politics, especially spatial distances between parties and the preferences of legislative elites, all computed from original legislative survey data. We 
find evidence that left-right polarization declined throughout much of the period under analysis, but made a resurgence in the last parliament (2014-2018). We also find evidence that politics, at least at the federal (Congressional) level, is very much "one-dimensional." These findings suggest quite strongly that Brazil's skyrocketing fragmentation cannot be linked to multiple issue cleavages. In the final section, we sketch an alternative explanation for accelerating hyperfragmentation.

\section{Sources of Endogenous Fractionalization: Competing Hypotheses}

Explaining varying levels of party-system fragmentation across countries- the traditional task in the literature-is not the same enterprise as explaining the accelerating hyperfragmentation of a single, already fractionalized system. For within-case analysis, the structure of issue cleavages provides us with several theoretical clues. If we think spatially about an established multiparty scenario, we can conceive of several ways in which new parties could populate unoccupied spaces. In other words, we need to gauge the potential emergence of "vacancies in the policy space" that can be occupied by new players. We advance several related hypotheses based on this perspective, and then complement these by posing an alternative hypothesis centered on the self-regarding strategies of ambitious political elites.

The first task of an issue-based account of fragmentation is to determine whether the dimensionality of the policy space is expanding or contracting. Under permissive electoral rules, increasing multidimensionality of the policy space can allow new parties to emerge and establish

themselves. ${ }^{6}$ For example, a classic argument about Western European party systems holds that after the 1970s, politics was no longer reducible to a single-left right dimension based mainly on state intervention in the economy; postwar generational change produced a second cleavage 
based on postmaterialist values. ${ }^{7}$ In this scenario, niche parties—defined as "parties that compete primarily on a narrow range of non-economic issues" ${ }^{\prime 8}$ - found it easier to achieve electoral expression. The Green parties are the most familiar example, but "backlash" movements such as nationalist and anti-immigration parties have also emerged, constituting a "silent revolution in reverse." ${ }^{9}$ Leaving aside the substantive content of these niches, we should expect party fragmentation to rise along with the number of salient dimensions in the party system. This inspires our Hypothesis 1 concerning Brazilian hyper-fragmentation: new parties appear to fill spatial positions not easily captured by the traditional left-right cleavage.

But what if the structure of political competition is found to be largely unidimensional, as it tends to be in most Latin American countries for which data exist? ${ }^{10}$ Even in this simplified scenario, "vacancies" can and do occur. Surplus fragmentation can be explained either by the advent of a centripetal trend (i.e. issue convergence or decreasing polarization) or a by centrifugal trend (i.e. rising political polarization). These hypotheses are two sides of the same coin: either trend opens windows of opportunity for new entrants in a one-dimensional policy space, contributing to advanced fragmentation.

When leading parties begin to converge on ideas or policy, they not only dilute their "party brands"11 but they also incentivize new parties to seize abandoned ideological spacesespecially in systems using PR rules. To some extent, this is what we have witnessed in Germany in the past decade, with The Left (Die Linke) outflanking the Social Democrats (SPD) on the progressive end of the party system and Alternative for Germany (AfD) outflanking the Christian Democrats on the right. Similarly, in Spain the policy similarities between the Socialists (PSOE) and the Popular Party (PP) opened up space for the emergence of Podemos and later Vox. In the US, the insurgent Tea Party wing of the Republicans pulled the party away from the center after 
2008 — and dissident progressives have had a reciprocal effect on the Democrats since 2016 - but the use of SMDP rules meant that proto-factions were uneasily contained within the existing two party-system. Yet whenever policy convergence between the main parties generates factional dissent and the electoral system is reasonably permissive, we should expect to see new party entrants emerge on the flanks of the "establishment." This yields the spatially derived Hypothesis 2a: fragmentation is caused by policy convergence among the traditional parties.

Alternatively, polarization could also be the culprit for increased fragmentation. If existing parties assume more extreme positions and there is increasing overlap of different issue cleavages, there might be room for splinter parties or new entrants to form in the center. A familiar though short-lived example is the UK in the wake of the 1979 victory by Margaret Thatcher. With the Conservative Party lurching to the right and the Labour Party tacking left under Michael Foot, the center space was ripe for the taking. Enter the Social Democratic Party, emerging from the moderate wing of Labour. The SDP then allied with the Liberals in the extremely polarized 1983 general election, leading to the highest vote fragmentation observed since 1929. This fractionalization of the vote occurred in a wide vacuum between the two dominant parties. In contrast to the convergence mechanism, under which we would expect to see new entrants at the unoccupied extremes, the polarization mechanism yields our Hypothesis 2b: fragmentation is explained by new entrants at the vacated center of the ideological space. Note that $\mathrm{H} 2 \mathrm{a}$ and $\mathrm{H} 2 \mathrm{~b}$ obey the same spatial logic.

Finally, it is possible that neither the multidimensional nor the single-dimension variant of these issue-based explanations gives us much leverage over our dependent variable. An alternative hypothesis is that hyperfractionalization is decisively unrelated to issue cleavages or the policy space. Under this hypothesis, fragmentation is produced by the re-sorting of existing 
political elites into different parties according to electoral or strategic interests that are decoupled from policy positions, and even from preferences of the electorate. If this is the case, we would expect to observe neither any increases in the dimensionality of the policy space, nor any monotonic relationship — whether positive or negative — between changes in polarization and changes in fragmentation. In fact, we would not even necessarily expect to see new parties forming. Fragmentation could be produced by the shrinking of the main parties and the swelling of previously marginal ones, even if the policy space is highly unidimensional. This yields our Hypothesis 3: fragmentation without cleavages. If fragmentation is unrelated to issue cleavages, then logically it must be driven by the purposive action of strategic elites: after all, even in the most institutionally permissive environments, new parties do not form spontaneously.

In the following sections, we assess the empirical implications of these four competing hypotheses by amassing elite survey data from almost 30 years of democratic experience in Brazil. We begin by briefly describing how party system fragmentation has evolved since redemocratization. We then assess whether there is any evidence of multidimensionality (or increasing dimensionality) in the Brazilian policy space. Finding no such evidence, we proceed to examine how (one-dimensional) polarization of the party system has varied over the period and whether there is any association, either positive or negative, between polarization and fragmentation. We subsequently test whether fragmentation has affected the center versus extremes of the issue space in different ways, and whether it has been driven by new entrants. The examination of these empirical questions allow us to discriminate between several possible drivers of Brazil's hyperfragmentation and assess whether it is explained by issue cleavages. 


\section{Trends in Party System Fragmentation}

Figure 1 reports the effective number of parliamentary parties (ENPP) in the lower house of Brazil's National Congress since the twilight of authoritarianism. ${ }^{12}$ Elections are held every four years, but due to conspicuous party switching between elections ${ }^{13}$ we report ENPP on an annual basis. The figure also reports the effective number of electoral parties (ENEP) in the ten elections since 1980. The 1982 election, it should be noted, was the last held under military rule, and although generally regarded as "fair," it was not entirely "free." 14 The 1986 election is considered the first democratic election in the period, even though it was conducted by a civilian government that was not directly elected.

The figure demonstrates extraordinary and rising fractionalization. Fragmentation has increased almost continuously with the exception of the $51^{\text {st }}$ and $52^{\text {nd }}$ Legislatures, following the 1994 and 1998 elections, respectively. Even this reprieve, however, could be simply a correction to the trend after an overshoot in the 1990 election or a temporary effect of the introduction of concurrent presidential and legislative elections (held together for the first time in 1994). This period also coincided with the taming of the persistently high inflation that had plagued Brazil since the early 1980s. In this improved economic scenario, the 1994 and 1998 elections were the only two cases of Brazil's eight democratic presidential elections that produced first-round victories (both by Fernando Henrique Cardoso). Yet after this minor pause, the process of secular fragmentation quickly resumed, with an impressively steep curve over the past two decades. ${ }^{15}$ 


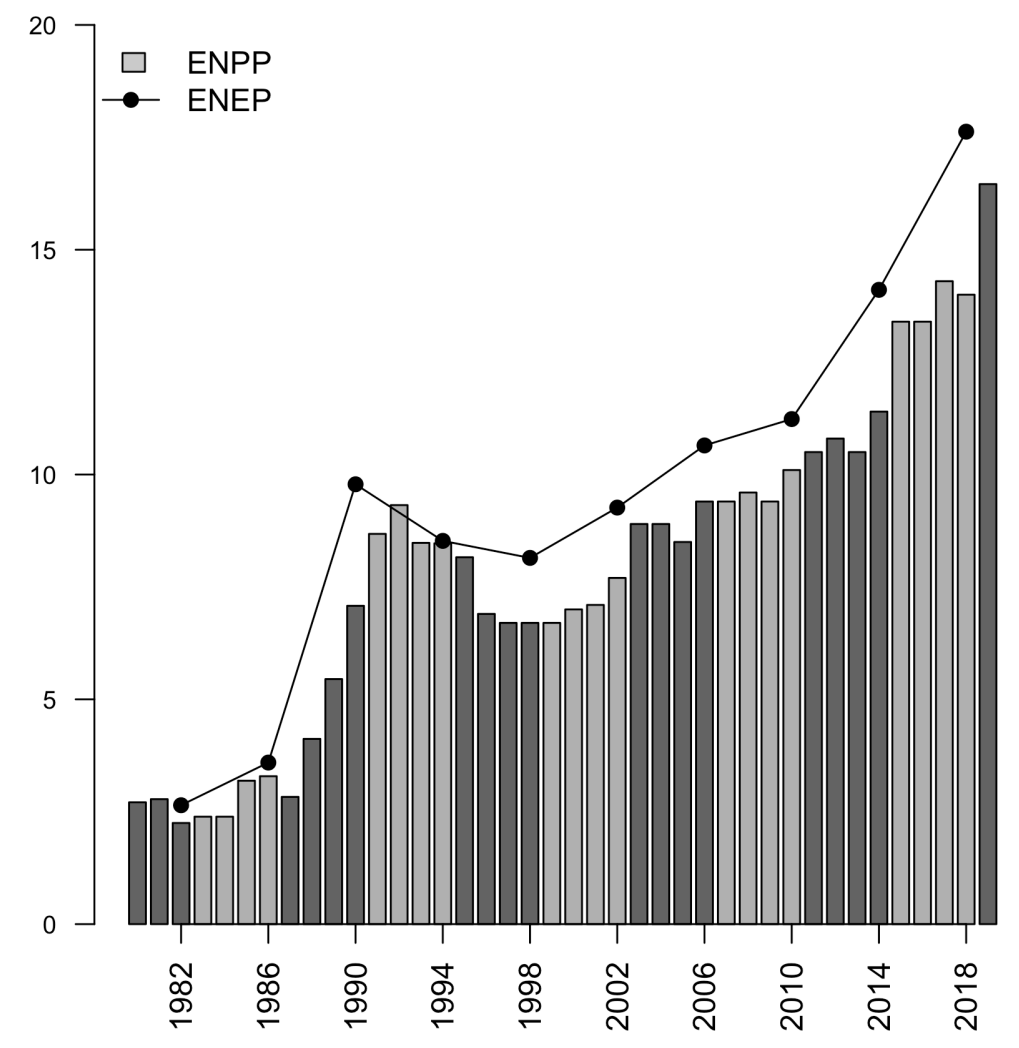

Figure 1: Effective Number of Electoral and Parliamentary Parties in Brazil, 1980-2019

Notes: the 2019 ENPP value reflects the seat composition resulting from the October 2018 elections, but does not incorporate party switching after deputies were seated on $1^{\text {st }}$ February 2019. Source: Electoral results for all elections are from the Tribunal Superior Eleitoral (TSE), and for early elections were compiled in Zucco (2015). Figures for ENPP through 1995 were obtained from Nicolau (1996, p. 78), and for later years were obtained from

\section{The Dimensionality of the Policy Space}

We now turn to potential accelerators of fractionalization. In order to assess any issue-based explanation of hyperfragmentation, it is important to gauge the dimensionality of Brazilian politics. Not only would an increase in the dimensionality of politics allow for new niche parties to form, but if politics is essentially multidimensional (even if the dimensionality is not increasing), parties can be formed to represent different bundles of issues that previously lacked advocacy. 
Rosas, for instance, discussed how multidimensional politics can lead to a larger number of parties, but went on to conclude from comparative legislative survey data that "programmatic differentiation can be captured by a single partisan dimension in most Latin American legislatures," including Brazil. ${ }^{16}$ Zucco and Lauderdale found that legislative behavior in Brazil can be described using only two dimensions, a single policy dimension and an additional government-opposition cleavage, which is purely strategic and not based on issues. ${ }^{17}$ Hence, their result points towards the existence of a single substantive dimension in the political space, which is also corroborated by most analyses based on recorded voting in the legislature. ${ }^{18}$

Yet survey data can reveal latent preferences that are concealed by floor voting in the assembly. Thus we rely on Waves 7 (2013) and 8 (2017) of the Brazilian Legislative Survey (BLS), which has been administered to members of Congress since redemocratization. Both waves included a number of substantive questions that allow us to probe the meaning of ideology and gauge the dimensionality of the policy space. We rely here on 20 substantive questions, which we grouped into five sets of issues. ${ }^{19}$

Traditional economic issues included four questions covering the degree of state intervention in the economy, redistribution, socioeconomic affirmative action, and whether citizen wellbeing is primarily the responsibility of the state or of individuals themselves. Classical Liberalism includes four questions about effort, competition, meritocracy, and entrepreneurship that were reproduced from the World Values Survey. Fiscal issues include preferences about spending and taxation in five policy areas. Under New Political Issues we included abortion, same-sex marriage, and race-based affirmative action. Finally, under the umbrella of International issues we included views on China, the role of the Brazilian development bank in supporting Brazilian companies abroad, foreign investment protection 
treaties, and on the desirability of stronger ties with the OECD vis-à-vis regional neighbors. As can readily be seen, the BLS casts an extremely wide net: if multidimensionality exists, these diverse questions should be capable of revealing it.

After adjusting the polarity of response scales so that higher values reflected "more conservative" positions, we combined items using principal component analysis to produce a single score for each topic. ${ }^{20}$ The result is a matrix of estimated positions on the five issue-sets covering 268 legislators. ${ }^{21}$

The policy space defined by these five bundles of issues is unambiguously onedimensional. This conclusion is based on several commonly used criteria to analyze the dimensionality of data matrices. Indicators ranging from the simple examination of the screeplots to "very simple structure" (VSS) analysis and parallel analysis (all reported in the Appendix), support this claim. More substantively, the linear associations between the scores and our independently derived estimate of left-right ideology (discussed in the next section) are all positive. This correlation is strongest for Traditional issues $(r=0.5)$ and weakest for classical Liberalism $(r=0.23)$, but in all cases the association is statistically significant $(p$-value $<0.01)$.

In fact, if we analyze Waves 7 and 8 of the BLS separately, we observe that the scores on the five issue-sets became more strongly correlated with each other and with the ideology estimates between 2013 and 2017. This "alignment" was particularly pronounced for Liberalism and International issues. ${ }^{22}$ Hence, politics, if anything, has become more one-dimensional and more structured along ideological lines even as fragmentation has continued to increase.

This leads us to ponder how many parties would be necessary to convey the diversity of opinions in the Brazilian Congress. We can examine this empirically by employing cluster analysis, which designates several techniques to form groups of observations such that intra- 
group differences on any one of several alternative metrics are minimized relative to inter-group differences. We employ, for this task, a routine to estimate the optimal number of clusters based on a technique known as "partitioning around medoids" (PAM), which is a more robust version of well-known $K$-means routines. ${ }^{23}$ Somewhat surprisingly to us given Brazil's extremely large number of legislative parties, the optimal number of clusters to classify the 271 responses in our analysis is $t w o$. As we report in the online Appendix, the two resulting parties would be very consistent in terms of their issue preferences, and about $59 \%$ of respondents would be in the right-leaning party.

Even if our clustering analysis is a somewhat arbitrary exercise, it is clear that the parliamentary issue space does not require the large number of political parties that currently exist, thus disconfirming H1. To put this more bluntly, the addition of new parties does not seem to fill any particular issue niche. Two decades ago, Mainwaring had already observed that almost all Brazilian parties were essentially catch-all parties; $;{ }^{24}$ this is still true today, except that there are nearly twice as many in Congress.

\section{Spatial Analysis: Locating Parties in One Dimension}

We now turn to our two related hypotheses about hyperfragmentation deriving from "vacancies" in the one-dimensional policy space. Our centripetal H2a predicts that vacancies emerge due to convergence of the traditional parties, and our centrifugal $\mathrm{H} 2 \mathrm{~b}$ predicts that space becomes available due to abandonment of the center. In order to assess these possible explanations, we deploy several indicators of party system polarization.

To track polarization, we rely on estimates of the ideological positions of the main Brazilian political parties in a one-dimensional space. The 20 survey questions discussed in the 
previous section allow us a glimpse of the substantive aspects of the policy space. However, they do not cover a long period of time, nor are they precise enough to serve as direct tests of the convergence $(\mathrm{H} 2 \mathrm{a})$ or polarization $(\mathrm{H} 2 \mathrm{~b})$ hypotheses.

We work instead with original estimates of the ideological positions of parties. We generate these by rescaling the answers given by legislators to survey questions that ask them to locate themselves and all main parties in the political system on an intuitive ideological scale that ranges from 1 (left) to 10 (right). Although these questions lack the substantive nuance of the previous analysis, they have been part of all eight waves of the BLS since 1990. Moreover, unlike roll-call votes in Congress, survey data are uncontaminated by the incumbent president's vote buying efforts. $^{25}$

The data for the estimation of the positions of parties consist of 17,932 placements of parties made by 950 unique survey respondents between 1990 and 2017. The model we use to estimate these updated system-wide positions differs only marginally from previous versions of these estimates, ${ }^{26}$ so we relegate the details to the online Appendix.

Our party-legislature estimates are proportional to simple averages of the raw placement of parties in each survey-year, but the rescaling has some advantages. We obtain standard errors about the estimates, which allow us to assess whether the perceived positions of two adjacent parties are in fact different. Rescaling also allows us to extract individual and legislator estimates on the same scale and, more importantly, produce estimates in a common space that allows for comparisons over time.

Figure 2 reports estimates for the main parties over the eight waves of the BLS graphically, and the numeric values are provided in the Appendix. For each party, the topmost 
observation is the earliest survey, and parties are ordered from top to bottom according to their most recent placement.

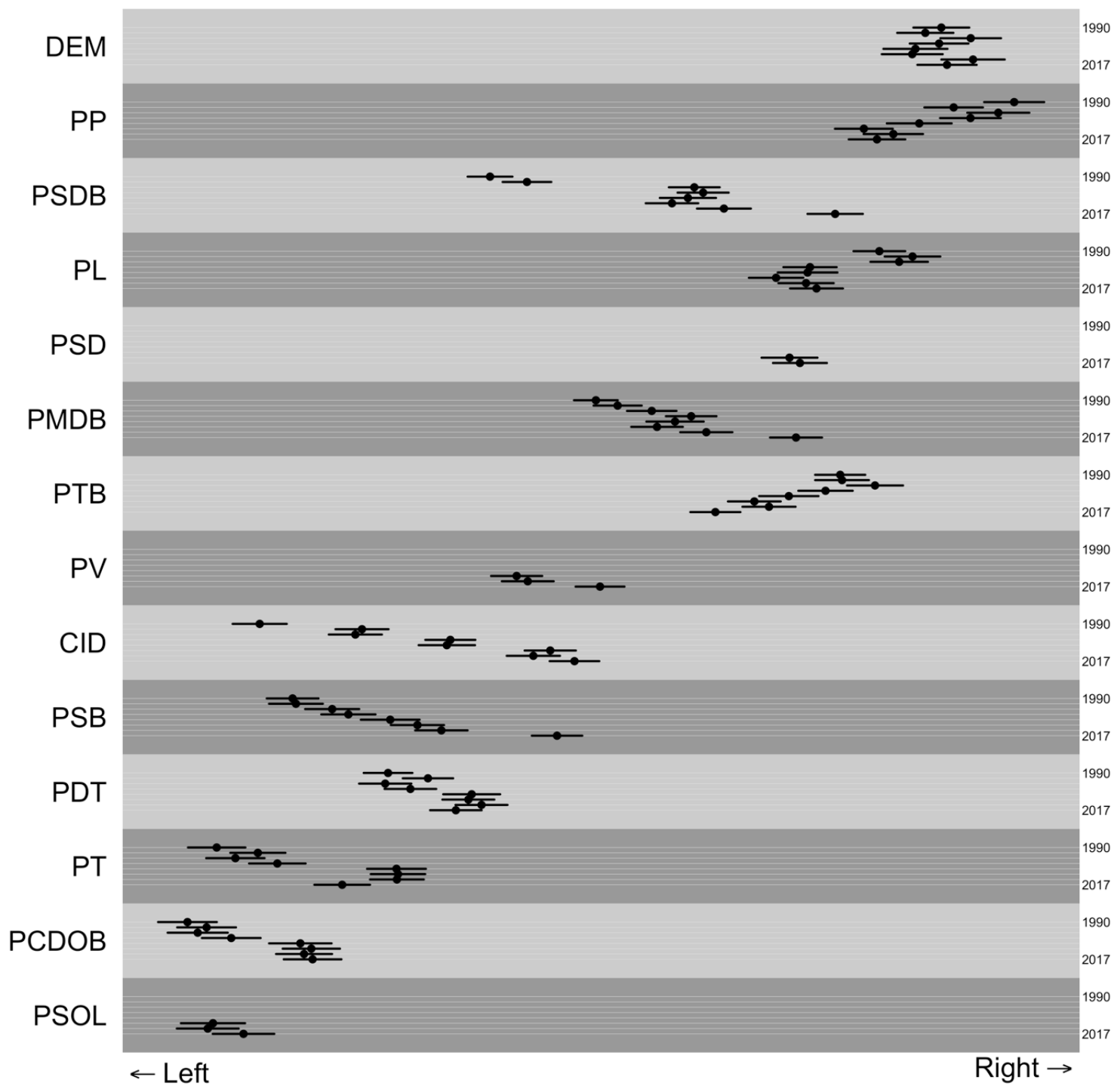

Figure 2: Estimated Left-Right Positions of Parties (1990-2017)

Notes: the maximum number of observations per party is eight, with the topmost observation corresponding to 1990 (Wave 1 of BLS) and the bottom one to 2017 (Wave 8 of BLS). Missing observations occur either because the party did not exist (e.g. the PSD was founded in 2011) or was too small to merit inclusion in the surveys (e.g. PV, PSOL in their early years). Parties are referred to by their most recent name; figure does not include all parties for which estimated positions are available. No estimate is available for the PSL (formateur party from 2019). Source: Brazilian Legislative Surveys.

Democrats (DEM, known as the PFL until 2007) is the only party among those observed in all waves that has essentially not moved. Until 2018, it was the country's rightmost major 
party. ${ }^{27}$ Almost all of the other main parties, in contrast, have moved toward the center over time. Other parties originally on the right (such as the PP, PTB, and PL) have drifted to the left, and parties originally on the left have shifted rightward, some of them quite decisively. On the left, even if PT, PCdoB and PDT halted their movement to the center after 2009, they are today less "extreme" than at the start of the series.

A simple visual inspection of these estimates suggests that polarization decreased over an initial period (covering roughly the first six waves of BLS) and then increased somewhat over the next two waves, although without returning to the baseline observed in 1990. Yet there are better ways to produce summary measures of polarization from party positions on a single ideological dimension. ${ }^{28}$ The simplest indicator of polarization is a measure of the maximal ideological distance (MID) using all parties in the system. ${ }^{29}$ Although this operationalization does not account for differences across the entire distribution of positions, it does generate an easily interpretable measure.

An important summary measure for multiparty settings is Dalton's polarization index (PI), which has gained significant traction in the recent literature. Dalton's index is a measure of how far parties are from the average position in the system, weighted by the importance of each party. ${ }^{30}$ Given the roughly $[-1,1]$ scale on which our party positions are measured, this index would assume a value of 0 when all parties occupy the same position on the left-right scale and 1 when all the parties are split between the two extremes of the scale. Differently from the range indicator, Dalton's PI is more sensitive to changes in seat shares of centrist as opposed to extremist parties.

One critique of Dalton's index and alternative indices based on standard deviations is that they focus on distances relative to the average position in the party system, whereas the concept 
of polarization would imply a focus on differences between parties. ${ }^{31}$ A more direct alternative, therefore, is the "mean absolute distance" (MAD). ${ }^{32}$ Measures such as MAD, which aggregate clusters of dyadic distances, tend to be sensitive to the number of parties. Since this number varies considerably in our sample, we computed a variant of the index that weights distances by party sizes, which we refer to as mean average absolute distance (MAAD).

In Table 1 we report the MID, PI, and MAAD computed using the distribution of seats in the last eight legislatures and party positions estimated from BLS data collected in the corresponding legislative elections (i.e. the columns under "System-Level"). ${ }^{33}$ We do not have ideology scores for every party that won seats, but our estimates always cover more than $90 \%$ of seats, and all of the leading parties.

Table 1: Polarization and Fragmentation by Legislature (1986-2014)

\begin{tabular}{|c|r|r|r|r|r|r|r|r|r|r|r|r|}
\hline \multicolumn{1}{|c|}{\begin{tabular}{c} 
Legislatures \\
\hline$\#$
\end{tabular}} & \multicolumn{4}{|c|}{$\begin{array}{c}\text { Ideology Estimates } \\
\text { Coverage (BLS) }\end{array}$} & \multicolumn{4}{c|}{$\begin{array}{c}\text { Polarization \& Fragmentation } \\
\text { (System-Level) }\end{array}$} & \multicolumn{4}{c|}{$\begin{array}{c}\text { Polarization \& Fragmentation } \\
\text { (11 Continuing Parties Only) }\end{array}$} \\
\hline 48 & 1986 & 1 & 97.4 & 13 & 1.89 & 0.57 & 0.74 & 3.29 & 1.89 & 0.60 & 0.73 & 4.48 \\
\hline 49 & 1990 & 2 & 97.4 & 14 & 1.85 & 0.58 & 0.56 & 7.08 & 1.71 & 0.60 & 0.56 & 6.30 \\
\hline 50 & 1994 & 3 & 98.3 & 11 & 1.83 & 0.65 & 0.84 & 8.47 & 1.83 & 0.65 & 0.84 & 6.36 \\
\hline 51 & 1998 & 4 & 97.1 & 11 & 1.69 & 0.56 & 0.49 & 6.70 & 1.69 & 0.56 & 0.49 & 6.33 \\
\hline 52 & 2002 & 5 & 95.6 & 11 & 1.42 & 0.46 & 0.52 & 7.70 & 1.42 & 0.46 & 0.52 & 7.95 \\
\hline 53 & 2006 & 6 & 95.5 & 13 & 1.60 & 0.44 & 0.47 & 9.40 & 1.38 & 0.42 & 0.45 & 7.93 \\
\hline 54 & 2010 & 7 & 92.9 & 14 & 1.75 & 0.46 & 0.56 & 10.10 & 1.53 & 0.44 & 0.54 & 7.64 \\
\hline 55 & 2014 & 8 & 96.5 & 20 & 1.61 & 0.47 & 0.48 & 11.40 & 1.45 & 0.48 & 0.49 & 8.41 \\
\hline
\end{tabular}

Source: compiled by authors from TSE and BLS data. The 11 continuing parties are PMDB, PT, PSDB, DEM, PP, PTB, PL, PDT, PSB, CID, and PCdoB.

These numbers provide additional insight into the dynamics of polarization. The most naive indicator (MID) conforms to visual inspection. This makes sense, as MID is simply the distance between extreme parties. Yet the relative weight of non-extreme parties has changed 
over time, and this explains why Dalton's PI diverges slightly. Using the PI measure, maximum polarization was reached in 1994. The linear correlation between MID and PI is strong $(r=0.72$, $p$-value $=0.045)$. The indices agree that system-level polarization was generally higher at the start of the time series, that the low point was reached sometime between 2002 and 2006, and that it has edged upward in the past decade. MAAD, moreover, tells a story that is almost identical to PI $(r=0.78, p$-value $=0.022)$, except that the recent upswing in polarization seems larger. This also makes sense: ideological distance between the PT and the biggest parties on the right has increased in recent years, and MAAD treats these distances as more relevant than does Dalton's PI.

This understanding is corroborated by a battery of questions about (perceived) political polarization in the country, included only in BLS8 in 2017. Politicians strongly agreed that polarization increased over the preceding four years in the traditional news media, on social media, in Congress, and in the Brazilian population as a whole. Close to $50 \%$ of legislators identified sharp increases in polarization in Congress and an additional 30\% identified a small increase.

\section{Fragmentation and Party Placements in One Dimension}

Table 1 also reports fragmentation statistics by legislature that show the constant expansion of the number of parties. ${ }^{34}$ The association between polarization and fragmentation (ENPP) is always negative but never statistically significant. ${ }^{35}$

If a preference-centered process is driving fragmentation in a unidimensional party system, and we observe a negative (even if weak) association between fragmentation and polarization, then the story would have to run along these lines: a decrease in polarization opened 
space for new parties at the flanks of the ideological space, which (given the consistently permissive institutional framework) were able to form, thus leading to increased fragmentation. In such a narrative, the appearance of new entrants at the extremes would tend to increase polarization - thus reversing the initial decrease in polarization that first opened the door for them. If this story were true, then we would expect to see two things: (1) polarization among older parties decreasing over time, and (2) the appearance of new party entrants near the right and left poles of the party system.

The last columns in Table 3 reports polarization and fragmentation measured only among the 11 parties for which we have ideological estimates in all eight waves of the BLS (i.e. the "continuing" parties). The similarity between polarization at the system level and what is registered among continuing parties suggests that the entrance of new parties neither offset the decrease in polarization we observe in the period, nor contributed to its increase in the last two legislatures. This means that the party system did, overall, become less polarized—so if a preference-based process was behind the increase in fragmentation, most new entrants should have appeared at the ideological extremes.

A return to Figure 2 shows that this conjecture is not supported by the data. We were able to estimate positions for several new parties that entered the system over the years. There were two entrants at the extreme left of the ideological dimension (PSTU and then PSOL), both of which were breakaways from the PT, but their very small size means that they contribute little to polarization indices (except for MID) or to measures of fragmentation. There have been larger new entrants on the right (PSC, PDC), though neither of them more extreme than the traditional DEM. Moreover, there have been several new entrants all over the spectrum, including centerleft (REDE), center (PV, PROS, SD), and center-right (PODE, PRB, PSD). 
Fractionalization, moreover, has increased markedly among the subset of continuing parties. That is, even without considering new entrants at all, the bloc of core parties in Brazil has become considerably more internally fragmented. It is quite a feat that a group of "only" 11 parties could produce an internal ENPP of 8.4 in the 2014 elections. In the last two decades, the number of parties necessary to form a minimum winning coalition in the Chamber of Deputies has increased from 4 to 8 . Given that the largest party won no more than $14 \%$ of seats in 2014 and $11 \%$ in 2018, we can now say that Brazil no longer has any large party, but, instead, a collection of several mid-sized parties and a huge number of small ones. This means that an impressive share of recent fragmentation in Brazil is explained not by new entrants, but by the changing size of the continuing players.

\section{Why So Many Parties?}

Why, then, is the number of parties in Brazil so incredibly high and continuously rising? The main electoral rules have remained stable since Brazil's return to democracy in the mid-1980s, social cleavages are not particularly politicized, and as we have systematically shown in the preceding sections, the evidence weighs strongly against preference-driven fragmentation. Politics is one-dimensional and, if anything, more one-dimensional than it has been before. Polarization has waxed and waned, but fragmentation has increased almost continuously. The general trend has been toward less polarization, but new entrants have appeared everywhere

across the left-right spectrum. Moreover, fragmentation would still look remarkable even if we disregarded the new entrants altogether.

Our "answer," in this section, is an attempt to connect the empirical dots. We start by returning to two particularly noteworthy aspects of Figure 1: (1) the relationship between the 
number of parties in Congress following each election and the number of parties in the electorate has been quite stable, and (2) the number of parties increased between elections in seven of the nine complete legislatures for which we have data.

The tight correlation between ENEP and ENPP suggests that the "mechanical" effects of the electoral system have not varied, which makes sense given that only marginal changes were made to the basic rules after 1986. This means that the increase in ENPP is driven more by the supply of competing parties than by greater ease in converting votes to seats. If the supply of parties was not driven by the structure of issue-cleavages, we argue here that it is driven by strategic considerations of politicians.

Why this focus on elite agency? Three characteristics of the Brazilian electoral system and executive-legislative relations make it far more enticing for most politicians to be a highranking member of a small party than a low-ranking member of a large one, and these incentives have intensified during the period under consideration.

First, being state leader of a small party is, for many politicians, a form of mitigation of electoral risks. Most politicians are "free agents" who possess personal electoral capital (i.e. votes and networks) that is portable across parties. ${ }^{36}$ Because their capital is so easily convertible, they are not intimately attached to any given label (with very few exceptions). Given the complexity of the open list PR system, a free agent stands to benefit from being able to "choose," at the last moment, which list she will compete in. Being the leader of a small party affords this possibility, as one can bargain with other parties to form joint electoral lists (coligações) until fairly close to the election, long after the deadline for politicians to switch parties. Alternatively, one can control access to the party ballot in order to remain the unchallenged "top dog" while including enough minor candidates to reach the electoral quotient. 
A lower ranking member of a larger party, in contrast, has little control over the formation of joint lists, and might find oneself in direct unwanted competition due to decisions made by those higher up in the party.

Second, even though the general PR rules have been stable, a slew of ancillary, less visible institutions have changed and increased the attractiveness of being a "big fish in a small pond." Particularly important has been the increase in public funds for campaigns. Brazilian parties began to receive public funds to finance their operations as far back as 1965; although the rules have undergone minor changes, the basic principle was always that funding would be divided among parties in proportion to their seats or votes won in the previous election. In 2007 there was a change in the allocation rules that favored smaller parties. ${ }^{37}$ Whereas in 2006 , some $66 \%$ of funds went to the four largest parties, in 2007 only $51 \%$ did. Since then, their combined share has declined to just over $40 \%$ of the total, though part of this decline reflects the greater fragmentation in Congress.

While one can see this increased dispersion of funds in Figure 3, the most striking change is the staggering volume of resources now available to parties. In the first decade of Brazilian democracy, public funding of parties was trivial. ${ }^{38}$ But then the party fund increased from $\mathrm{R} \$ 4.5$ million in 1994 (values adjusted for inflation) to R 741 million in 2017, with sharp upticks in 1996, 2011, and 2015. Figure 3 does not include the implicit value of free air time on radio and TV, or the recent creation of a separate public fund for campaign finance, which in 2018 (the first election for which it was in place) represented an additional $\mathrm{R} \$ 1.7$ billion (more than twice the value of the party operations fund). ${ }^{39}$ 


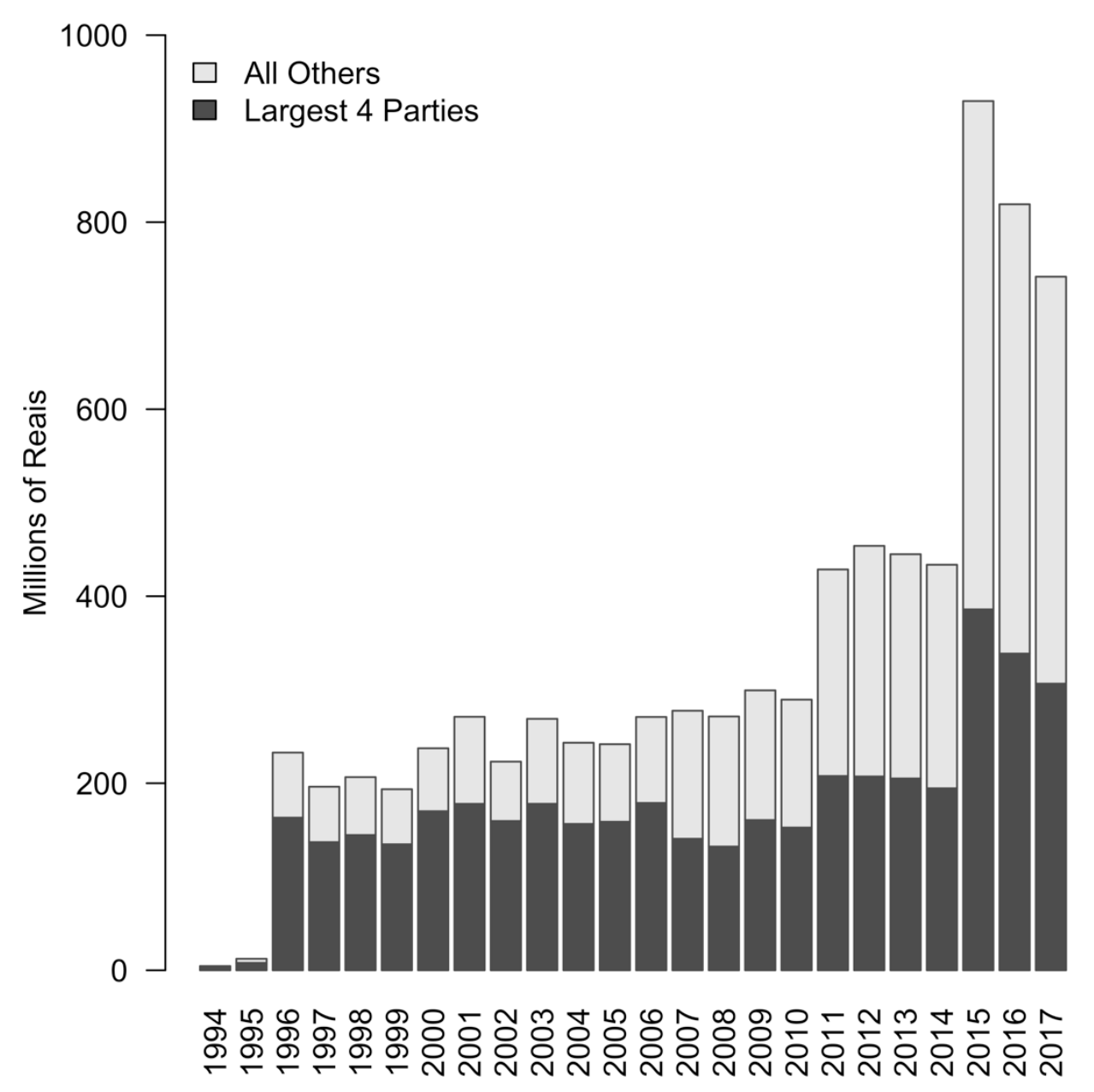

Figure 3: Allocations from Official Public Party Fund (1994-2017)

Notes: Data were obtained from the TSE (http://www.tse.jus.br/partidos/fundo-partidario-1/fundo-partidario). Values were adjusted for inflation and converted to BRL of December 2017 (3.88 BRL=1 USD). The decline in the final two years is driven mainly by adjustment for inflation.

Hence, not only have funds been distributed in a more decentralized fashion, but the absolute value of these resources has skyrocketed. This has made control over party organization even more important than in the beginning of the democratic period, because since 1995 parties have enjoyed enhanced discretion with regard to how they allocate their dedicated public funding. Most parties prefer to direct the bulk of these resources to the subnational level, with the more nationally oriented PT being a notable exception. ${ }^{40}$ The easiest and quickest route to 
control these funds is to become the state-level leader of a small party — not to rise patiently through the ranks of a larger one.

Finally, executive-legislative relations in Brazil developed as a very particular case of “coalitional presidentialism.” Only two parties occupied the presidency from 1994 until 2016, and the presidency has disproportionate control over resources important for the survival of all politicians. We do not intend to explain why this situation came to be, but it meant that the dozens of non-formateur parties essentially operated under a different logic in which extracting resources from the presidency via legislative bargaining was the modus operandi. ${ }^{41}$ While one could imagine that larger parties would have an advantageous bargaining position, the fact that no party has come even close to holding a majority of the seats meant that coalitions have always been highly internally fragmented - thus mirroring the overall structure of Congress. Given that presidents have attempted to insure against defections by building oversized coalitions, ${ }^{42}$ they invest time and resources in wooing even the smallest of parties. The success of microparties at playing this game naturally incentivizes imitation, by both ambitious backbenchers stuck in larger catch-all parties and electorally potent free agents acting largely on their own. The combination of oversized coalitions with shrinking parties has thus afforded more politicians the chance to "sit at the bargaining table."

The mutually reinforcing effects of these three factors have been explosive, with the effect that fragmentation has spiraled upward from a high starting point. Rules that incentivize control over party lists and coalition formation stable have been in place since democratization in the 1980s. Given that politicians themselves crafted these rules, the notional "equilibrium" number of parties in the system was benchmarked at a higher level than one might expect based on social cleavages and preference structures alone. These institutions provided an initial nudge 
toward increasing fractionalization even as the core electoral rules remained stable. As party system fragmentation increased in the 1990s, it then altered the executive-legislative bargaining environment considerably, further increasing the value of control over small parties. Finally, in the emerging context of robust coalitional politics with shrinking formateur parties, radical changes in party finance over the last decade kicked the process into overdrive. For a very large subset of Brazilian politicians, now more than ever, it literally pays to be one's own leader. ${ }^{43}$

This account resembles an "arms race" among ambitious politicians, with microparties as the weapon of choice. This metaphor has a number of empirical implications. We should expect to see an increase in the number of lists competing in elections over time, as more politicians attempt to "go it alone" (or with minimal competition) instead of pooling resources with others. This is confirmed in the data from the six elections for which we have complete information on all candidates that competed in elections for the Câmara de Deputados. The number of state-level parties contesting elections increased continuously from 513 in 1998 to 623 in 2010 before jumping to 776 in 2014 and 875 in 2018. Clearly, the supply of parties has increased continuously—and particularly dramatically in the last two electoral cycles—which is compatible with a story about individually driven politicians empowered by public money.

If our account is plausible, we should also expect to see an increase in the number of state-level parties that are dominated by a single politician. While identifying all parties that are "controlled" by a single politician involves some degree of subjectivity, we can very straightforwardly count the number of state-level parties that elect only one representative to the 513-seat Chamber of Deputies. We refer to this phenomenon as one-member state delegations (hereafter OMSDs). ${ }^{44}$ The OMSD indicator is our proxy for the "big fish in a small pond" path to Congress. We note that OMSDs should be relatively rare in a country in which average district 
magnitude is so high. ${ }^{45}$ Moreover, their existence is not a necessary feature of increased fragmentation — which could result, for instance, from parties choosing to specialize by competing in different geographical niches. Yet trends in the frequency of OMSDs can inform us about changing patterns of party politics.

As we have explained, the value of controlling the ballot as a risk-mitigating strategy has remained more or less constant over the period studied, but the importance of controlling party funds has increased dramatically in recent years. Hence, we should expect to see a continuous expansion of OMSDs and an acceleration in more recent elections. Our expectations are supported by the data presented in Figure 4. There was an initial rise in OMSDs at the end of the military rule, when new parties were first allowed to form. Expansion then continued at a steady pace before accelerating markedly after 2010 . This recent uptick is evidence against territorial specialization by parties as the driver of fragmentation: it is much more likely the result of a huge increase in the amount of public finance that can be sequestered by ambitious individuals who can control their party within their home states. 


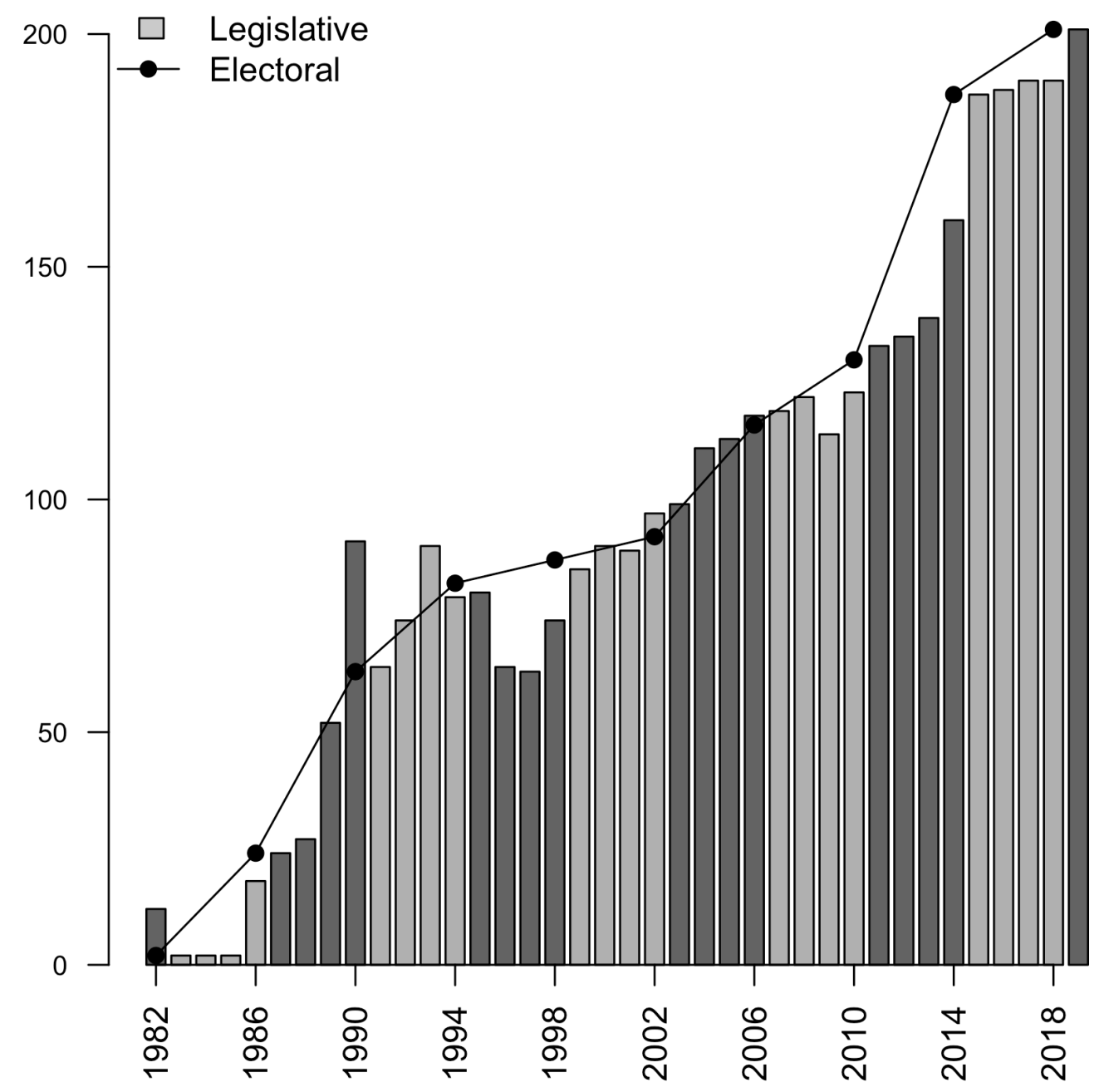

Figure 4: One-Member State Delegations to the Chamber of Deputies (1982-2019)

Notes: Electoral OMSDs (line) are computed from electoral results. Legislative OMSDs (bars) reflect interelectoral changes such as party switching, vacancies, and substitutions. Legislative OMSDs are computed at the start of each legislative year from data obtained in legislative records (1982-1988) and roll-call votes (1989-2019). There were 479 deputies elected in 1982, 487 in 1986, 503 in 1990, and 513 in all elections since 1994.

The rising number of OMSDs in non-electoral years is also noteworthy. It suggests that OMSDs are produced by a combination of electoral strategy and inter-electoral party switching. In fact, the share of party switchers is greater among OMSDs than among larger state delegations in all eight legislative sessions for which we have complete party switching data (i.e. since 1990, 
shown in the online Appendix). Incumbent legislators, it seems, also change parties in order to produce OMSDs: big fish can very easily jump into smaller ponds.

OMSDs are a specific type of microparty, but not the only possible type, so using OMSDs as a proxy for personal dominance has some limitations. What really matters for our argument is the degree of intra-list dominance by internal heavyweights. If OMSDs reflect attempts to be one's own boss, we should expect to see very personalized vote patterns within parties - as indicated by a high Herfindahl-Hirschman index (HHI) of vote concentration and/or by large differences between the first- and second-placed candidates within the party. ${ }^{46}$ If, on the other hand, OMSDs are just traditional parties in decline or new ones in emergence (that is, complex organizations that we are just observing on the way up or on the way down), then their internal vote distributions should not be very different from those parties that elect more than one candidate.

Examination of the voting patterns across all state-level parties that contested the six elections for which complete results are available (1998 to 2018, inclusive) reveals that parties that elected only one candidate score much higher on both measures of concentration than those that elected more than one candidate. OMSDs have much higher mean vote concentration indices (0.558 vs. 0.234$)$ and much larger average differences between first- and second-placed candidates $(50.55 \%$ vs. $10.79 \%$ of the aggregate party vote $) .{ }^{47}$

Admittedly, a few OMSDs do rank low on these indicators, suggesting that they are nothing more than traditional parties on the downswing. This is the case of the once-mighty PT in Rio de Janeiro state, which elected only one deputy (former governor Benedita da Silva) in 2018. The Rio de Janeiro branch of the party recorded a very low HHI of 0.13 , the seventh lowest among the 201 OMSDs in 2018. This means that Benedita - a committed member of the 
PT since 1981—shared electoral support with other viable petistas, but the crumbling party managed to elect only one deputy from Rio.

Yet Benedita's case is atypical of OMSDs. Most OMSDs display absurdly high values on intra-list dominance, which can be taken as evidence of intentionality to produce a singlemember outcome. Frequently these OMSDs result from either coalitional bargaining or blatant self-representation. Deputy Cleber Verde (PRB, state of Maranhão) is a good example of the former tendency. Originally a member of the PT in 1989, Verde switched to the PV in 1996 and then drifted through a series of nondescript "parties for rent": the PST in 1998, the PAN in 1999 (on whose label he won his first election to Congress in 2006), and the PTB in 2007. He was reelected to Congress by the PRB in 2010, 2014, and 2018, each time as the sole PRB federal representative from Maranhão. In 2014, while serving as PRB party president in the state, he aligned his party with protest candidate Flávio Dino (PCdoB), whose election to the governorship ended 40 years of dominance by the Sarney clan in the state. Two years later, Verde convinced vice-governor Carlos Brandão (PSDB) to switch into the PRB, sealing the coalition for Dino's reelection in 2018. In the same year, Verde ran for the Chamber of Deputies on the PRB list that he himself crafted in his role as party president, and was reelected to his OMSD status with 101,806 votes (the next-highest PRB candidate received a paltry 1,438 votes, giving the state party an astonishing HHI of .97). Verde's PRB-denominated assets now include the vice-governorship and 14 municipal mayors, but no less important are his unchallenged control over the PRB party list in proportional elections and his control over local party finance (donations from his own party covered $86 \%$ of the costs of his personal reelection campaign in 2018). ${ }^{48}$ These two factors buttress his safe seat in Congress. Verde is a typical example of a 
politician who has built and now "owns" a state microparty, and who also trades it successfully on the market for coalitional support.

An example of traditional self-representation is provided by Deputy Magda Mofatto (PL, state of Goiás), the wealthiest member of the Chamber of Deputies by declared assets. She and her partner ${ }^{49}$ Flávio Canedo are property developers in the spa town of Caldas Novas, where they own numerous hotels, condos, and theme parks, as well as local TV and radio stations. Canedo is the state president of the PL in Goiás despite having been convicted of torture in 2013; he remains free while his legal appeals continue ${ }^{50}$ Mofatto served on the city council as a member of the PMDB and PSD before winning election as mayor on the PTB ticket in 2004. She was removed as mayor after being found guilty of vote-buying, but this did not prevent her from returning to the city council in 2008. Mofatto then moved on to Congress, elected by the PTB in 2010 and by the PL in 2014 and 2018. Her partner Canedo was able to give her the memorable candidate number of 2222 (the number 22 representing not only her party but the caliber of her favorite pistol). A licensed pilot, Mofatto commutes weekly to Brasília in her own helicopter (with fuel paid for by the Chamber of Deputies), yet her real interest is in the local politics of Goiás where her business empire is based. ${ }^{51}$ Her political group has 19 mayors in Goiás and is valuable to both governor Ronaldo Caiado (DEM) and president Jair Bolsonaro (PSL), but its sole representative in Brasília is Mofatto herself. In fact, of the 229 candidates who competed to fill Goiás' 17 seats in the Chamber of Deputies in 2018, Mofatto was the only candidate nominated by the PL, thus triggering a massive contribution from her party's publicly funded campaign budget (Fundo Especial de Financiamento de Campanha). ${ }^{52}$ The PL is in fact the fourth electoral vehicle that Mofatto has used, and she could easily recreate her political group 
under a dozen other party labels, or simply launch a new one. Hers is a classic case of selfrepresentation and an OMSD by design.

Data from the last six elections suggests that a vast majority of the OMSD are of the Mofatto and Verde (intentional) type rather than that of the Benedita (accidental) type. More than $75 \%$ of OMSDs have vote concentration patterns higher than that of the $75^{\text {th }}$ percentile of the parties that elected more than one candidate, ${ }^{53}$ and this share has remained stable over the years. Thus, our simple indicator gives us a good sense of how common the big fish phenomenon has become. ${ }^{54}$ The typical OMSD is not an embryonic party intending to grow, but rather a truly one-person enterprise.

Even if the number of OMSD that are really one-person parties is only $75 \%$ of what was reported in Figure 4, the phenomenon is on the rise-and is even more pervasive than what the current composition of the Chamber of Deputies suggests. State parties that elected no candidates are much more similar to OMSDs than they are to larger parties. For these unsuccessful lists, the average HHI over the six elections for which we have data is 0.475 , and the mean difference between first- and second-placed candidates is $37.37 \%$, but levels of concentration with these parties have been steadily rising. Seen in this light, the OMSD vocation exists in hundreds of other small state-level parties that fail to elect a single candidate. The waiting room of Congress is populated by aspiring free agents, not by party builders investing in collective action.

As a result, it is not surprising that OMSDs now make up a large share of the total Chamber of Deputies caucus of several parties. As of 2019, in the PTB, Podemos, Solidariedade, and PSC, OMSDs account for 60, 73, 85 and 100\% of the national parliamentary party, respectively. These parties operate more like "franchises"-federations of independent investors who happen to own a local branch — than truly collective enterprises. At the other extreme, we 
find that in more established parties such as the PT and MDB, as well as in Jair Bolsonaro's new PSL (an upstart "outsider" party with non-professional politicians), the OMSD share is much lower $(24 \%$ or less $)$.

To summarize, while OMSDs can occasionally result from the shrinkage of traditional parties, they are more often the result of strategic action by ambitious politicians. This action can be motivated by list control, by coalitional bargaining, or by a desire to capture public funding, all of which add up to greater electoral security for elites. The result is that $40 \%$ of Brazil's lower house is now made up of deputies who are the only federal representatives of their state-level parties, a proportion that has doubled in the last decade. Examination of this phenomenon highlights key incentives driving the hyperfractionalization of the national party system.

\section{Conclusions: Accounting for Hyperfractionalization}

What explains the hyperfragmentation of an already robust multiparty system? Unlike the more common task of explaining variation in fragmentation across party systems, our question required sustained within-case analysis. For the case of Brazil, we have found that hyperfragmentation is explained neither by changing social cleavages nor by emerging issue cleavages. With regard to key issues of public policy, Brazilian party politics is essentially unidimensional, leading us to reject H1. In fact, given rising polarization in Congress over the past decade, the policy space has become more one-dimensional than in the early years of democracy. Ideationally, legislators could be sorted into just two parties based on their stated preferences. Surplus fragmentation is not explained by new spatial vacancies (resulting from either convergence or polarization) within the established one-dimensional space, leading us to reject $\mathrm{H} 2 \mathrm{a}$ and $\mathrm{H} 2 \mathrm{~b}$. 
The evidence instead favors our alternative hypothesis of "fragmentation without cleavages" (H3), and we sought to identify the likely factors undergirding this finding. Recent hyperfractionalization is linked to (1) new forms of risk mitigation by ambitious subnational politicians, mainly as a response to the proliferation of pre-electoral coalitions in PR elections; (2) the availability of massive amounts of state funding for party operations, which is itself a consequence of prior fragmentation but also (very recently) a response to judicial regulation of private campaign finance; and (3) at the macropolitical level, the consolidation of coalitional presidentialism and a functional need for oversized coalitions in Congress. With regard to this third factor, we note that the legislative position of formateur parties has continued to deteriorate: presidential parties managed to elect a quarter of seats on average in the 1990s, but this average has fallen by half in the $21^{\text {st }}$ century. With little more than a tenth of Congressional seats now held by the formateur, the president's struggle for legislative support is the central fact of national politics. This leads factions and individuals to believe — probably correctly—-that their negotiating position in the ongoing struggle to capture federal resources is best served by dominating a small party. About $40 \%$ of current deputies do exactly that, and there is a vast number of unsuccessful candidates trying to do the same.

These factors point to a scenario of "endogenous fractionalization," i.e. a party system in which fragmentation begets further fragmentation. They help us understand how Brazil has "expanded its lead" in the global league table of fragmentation. But could this scenario be reproduced elsewhere? The potential scope conditions, which we outline below, are restrictive but not exclusive to Brazil.

The first scope condition is undoubtedly a set of permissive electoral institutions (i.e. high district magnitude, low or nonexistent electoral threshold, low barriers to new party 
registration) that would raise, or remove, any expected "natural ceiling" for system-level fragmentation. A second condition might be political decentralization, given that even the most programmatic parties organize the bulk of their campaign activity—leaving aside presidential competition, which is the domain of a small subset of national contenders-around PR elections in subnational units. When funding is directed to the subnational level, incentives to fractionalization can multiply, and the aggregation of district-level "fragmentations" elevates the national ENPP. A third scope condition would be some reasonable degree of legislative autonomy, especially budgetary influence, such that party politicians can —if they so wishredirect state resources toward party activities in a way that makes even the smallest microparty financially viable. A fourth scope condition would be the predominance of coalitional politics, both in terms of preelectoral coalitions and in terms of governing coalitions in the legislature. Preelectoral coalitions drive ambitious politicians to try to maximize control over list composition, and postelectoral coalitions drive presidents to negotiate for floor support in Congress. In other countries practicing coalitional presidentialism, notably Chile, informal institutions have emerged to coordinate both preelectoral and postelectoral interparty alliances. ${ }^{55}$ Yet in Brazil such allocative mechanisms are largely absent, generating predictably high levels of uncertainty across individual, partisan, and coalitional actors.

In short, while party fragmentation has been rising slowly but surely almost everywhere in the world since the Third Wave of democratization, we suspect that in certain institutional environments there is an inflection point beyond which high fragmentation will spiral into hyperfragmentation. In the last decade, Brazil has found this inflection point and surpassed it.

\section{NOTES}


Cesar Zucco Jr. wishes to thank the Rede de Pesquisa Aplicada of the Fundação Getúlio Vargas for research funding. The authors are grateful to Rodrigo Lenz, Nathália Passarinho, and Joaquim Meira for research assistance, and to David Doyle for comments on an early version of the article. The online Appendix and replication materials for the analysis in this paper are available in Cesar Zucco's Dataverse (https://doi.org/10.7910/DVN/G2RADZ). Complete data from the Brazilian Legislative Surveys are deposited in the project's Dataverse (https://dataverse.harvard.edu/dataverse/bls).

${ }^{1}$ Scott Mainwaring, Timothy J. Power, and Fernando Bizzarro, “The Uneven Institutionalization of a Party System: Brazil,” in Scott Mainwaring, ed., Party Systems in Latin America: Institutionalization, Decay, and Collapse (New York: Cambridge University Press, 2018), 164200. We report the full names of all parties in the online Appendix.

${ }^{2}$ Octavio Amorim Neto and Gary W. Cox, "Electoral Institutions, Cleavage Structures, and the Number of Parties," American Journal of Political Science, 44 (January 1997), 149-74.

${ }^{3}$ Michael Coppedge, "District Magnitude, Economic Performance, and Party-System Fragmentation in Five Latin American Countries," Comparative Political Studies, 30 (April 1997), 156-85.

${ }^{4}$ Scott Mainwaring, Rethinking Party Systems in the Third Wave of Democratization: The Case of Brazil (Stanford: Stanford University Press, 1999).

${ }^{5}$ Natália Bueno and Thad Dunning, "Race, Resources, and Representation: Evidence from Brazilian Politicians," World Politics, 69 (April 2017), 327-65.

${ }^{6}$ Jeremy J. Albright, "The Multidimensional Nature of Party Competition," Party Politics, 16 (November 2010), 699-719. 
${ }^{7}$ Ronald F. Inglehart, “Changing Values Among Western Publics from 1970 to 2006,” West European Politics, 31 (January-March 2008), 130-46.

${ }^{8}$ Markus Wagner, “Defining and Measuring Niche Parties,” Party Politics, 18 (November 2012), 845-64.

${ }^{9}$ Ronald F. Inglehart and Pippa Norris, "Trump and the Authoritarian Populist Parties: The Silent Revolution in Reverse," Perspectives on Politics, 15 (June 2017), 443-54.

${ }^{10}$ Guillermo Rosas, “The Ideological Organization of Latin American Legislative Parties: An Empirical Analysis of Elite Policy Preferences," Comparative Political Studies, 38 (September 2005), 824-49.

${ }^{11}$ Noam Lupu, Party Brands in Crisis: Partisanship, Brand Dilution, and the Breakdown of Political Parties in Latin America (New York: Cambridge University Press, 2015).

${ }^{12}$ Brazil is a presidential and federal system with a bicameral legislature at the national level. Parties also contest gubernatorial elections and unicameral assemblies in 27 states, as well as mayoralties and local councils in over 5,500 municipalities.

${ }^{13}$ Carlos Ranulfo Felix de Melo, Retirando as cadeiras do lugar: Migração partidária na Câmara dos Deputados, 1985-2002 (Belo Horizonte: Editora UFMG, 2004).

${ }^{14}$ See David V. Fleischer, “Constitutional and Electoral Engineering in Brazil: A Double-Edged Sword," Inter-American Economic Affairs, 37 (Spring 1984), 3-36.

${ }^{15}$ The sharp increase in fragmentation is not an artefact of the conventional Laakso-Taagepera ENP index. We show in the online Appendix that the trajectory of fragmentation in Brazil is no less explosive under alternative measures.

${ }^{16}$ Rosas, p. 836. 
${ }^{17}$ Cesar Zucco Jr. and Benjamin E. Lauderdale, "Distinguishing Between Influences on Brazilian Legislative Behavior,” Legislative Studies Quarterly, 36 (August 2011), 363-96.

${ }^{18}$ See, for example, Argelina Figueiredo and Fernando Limongi, Executivo e Legislativo na nova ordem constitucional (São Paulo: Editora FGV, 1999).

${ }^{19}$ The full text of the questions is provided in the online Appendix. We grouped the variables a priori, and subsequently performed minor rearrangements following exploratory factor analysis. ${ }^{20}$ Diagnostics suggest that each of the issue sets was clearly one-dimensional.

${ }^{21}$ There were a total of 289 respondents across the last two waves of the BLS. However, we excluded legislators for which we did not have at least two items in each of the five issue sets. ${ }^{22}$ For example, the linear correlation coefficient between left-right ideology and Liberalism increased from $r=0.06$ in BLS7 to $r=0.4$ in BLS8. Similarly, the linear correlation between ideology and International issues rose from $r=0.18$ to $r=0.39$.

${ }^{23}$ For an introduction, see Leonard Kaufman and Peter J. Rousseeuw, "Partitioning Around Medoids (program PAM)," chapter 2 in their Finding Groups in Data: An Introduction to Cluster Analysis (New York: Wiley, 1990). Here we employ the default "average silhouette width" criterion in the pamk function in the fpc package for R; see Christian Hennig, "fpc: Flexible Procedures for Clustering,” R package version 2.1-11 (2018), available https://CRAN.R-project.org/package=fpc. Using the alternative Calinski-Harabasz criterion yields exactly the same results, and hierarchical clustering indicates the same optimal number of clusters and classifies $85 \%$ of the legislators in the same way.

${ }^{24}$ Mainwaring, 1999.

${ }^{25}$ Zucco and Lauderdale; see also Cesar Zucco Jr., "Ideology or What? Legislative Behavior in a Multiparty Presidentialist Setting," Journal of Politics 71 (July 2009), 1076-92. 
${ }^{26}$ Timothy J. Power and Cesar Zucco Jr., "Elite Preferences in a Consolidating Democracy: The Brazilian Legislative Surveys, 1990-2009.” Latin American Politics and Society, 54 (Winter 2012), 1-27.

${ }^{27}$ In October 2018, Jair Bolsonaro-universally acknowledged as the most hard-line rightist leader since the end of military rule_-was elected president. His minuscule Social Liberal Party (PSL), a hastily assembled coattails movement with only one congressman in 2018, surprisingly won the largest share of votes and the second largest share of seats for the Chamber of Deputies. We do not yet have an ideology estimate for the PSL, but there is every reason to believe that it will acquire a reputational position to the right of DEM.

${ }^{28}$ For estimations of party positions using manifestoes, see Ian Budge, David Robertson, and Derek Hearl, eds., Ideology, Strategy, and Party Change: Spatial Analyses of Post-War Election Programmes in 19 Democracies (New York: Cambridge University Press, 1987) and HansDieter Klingemann, "Political Parties and Party Systems," in Jacques Thomassen, ed., The European Voter: A Comparative Study of Modern Democracies (Oxford: Oxford University Press, 2005), 22-63. For placements of parties by voters in comparative surveys, see Russell J. Dalton, “The Quantity and the Quality of Party Systems: Party System Polarization, Its Measurement, and Its Consequences," Comparative Political Studies, 41 (July 2008), 899-920.

${ }^{29}$ Peter Mair, "Searching for Positions of Political Actors: A Review of Approaches and a Critical Evaluation of Expert Surveys," in Michael Laver, ed., Estimating the Policy Position of Political Actors (New York: Routledge, 2001), 10-30; Rune Sørensen, "Political Competition, Party Polarization, and Government Performance," Public Choice 161 (December 2014): 42750. 
${ }^{30}$ Dalton, p. 906 . Dalton calculated using his PI using a different ideology scale (0-10), whereas our raw data (rescaled BLS party placements) have values between -1 and 1 . Here we employ an adapted version, computed simply as $P I={\sqrt{s s_{i}\left(x_{i}-\bar{x}\right)}}^{2}$, with $\mathrm{ss}_{\mathrm{i}}$ and $\mathrm{x}_{\mathrm{i}}$ being the seat share and left-right position of party I, and $\bar{x}$ the average position in the party system.

${ }^{31}$ Jocelyn Evans, "In Defence of Sartori: Party System Change, Voter Preference Distributions and Other Competitive Incentives," Party Politics 8 (April 2002), 155-74.

${ }^{32}$ Donald Gross and Lee Sigelman, "Comparing Party Systems: A Multidimensional Approach." Comparative Politics, 16 (July 1984), 463-79.

${ }^{33}$ We used the party composition at the start of each BLS survey. Almost identical results obtain using vote shares and the BLS data for the legislature that followed.

${ }^{34}$ These values differ slightly from those in Figure 1 because they reflect the composition of Congress during fieldwork for each of the BLS surveys.

${ }^{35}$ Using the data in Table $1, r=-0.44, p$-value $=0.272$ for MID; $r=-0.51, p$-value $=0.19$ for PI; and $r=-.42, p$-value $=0.29$ for MAAD.

${ }^{36}$ Lucas Novaes, "Disloyal Brokers and Weak Parties," American Journal of Political Science 62 (January 2018), 84-98.

${ }^{37}$ Maria do Socorro Sousa Braga and Adla Bourdoukan, "Partidos políticos no Brasil: organização partidária, competição eleitoral e financiamento público," Perspectivas 35 (JanuaryJune 2009), 117-48.

${ }^{38}$ For this reason Figure 3 omits earlier years. Allocations from the party fund in the late 1980s and early 1990s were stable and were slightly above 1 million in 2017 BRL. See Mauro Campos, "Democracia, partidos e eleições: os custos do sistema partidário-eleitoral no Brasil," doctoral thesis, Department of Political Science, Federal University of Minas Gerais (2009), p. 58. 
${ }^{39}$ The Fundo Especial de Financiamento de Campanha (FEFC) was created by Congress in 2017 as a response to a 2015 Supreme Court decision prohibiting campaign contributions by private firms. We report the 2018 FEFC allocations by party in the online Appendix. In September 2019, Congress began debating a possible doubling of the FEFC to R 3.7 billion for the municipal elections of 2020.

${ }^{40}$ Braga and Bourdoukan, 2009; Pedro Floriano Ribeiro, Dos sindicatos ao governo: a organização nacional do PT de 1980 a 2005 (São Paulo: UFSCar/FAPESP, 2010).

${ }^{41}$ Fernando Limongi and Fabricio Vasselai, "Entries and Withdrawals: Electoral Coordination across Different Offices and the Brazilian Party Systems," Brazilian Political Science Review, 12 (November 2018), 1-27.

42 Timothy J. Power, “Optimism, Pessimism, and Coalitional Presidentialism: Debating the Institutional Design of Brazilian Democracy," Bulletin of Latin American Research 29 (January 2010), 18-33; Fernando Meireles, "Oversized Government Coalitions in Latin America." Brazilian Political Science Review 10 (November 2016), 1-31.

${ }^{43}$ This is entirely compatible with the finding by Limongi and Vasselai that the effective number of lists contesting presidential and gubernatorial elections at the state level has remained roughly stable over the years, whereas that of lists contesting legislative elections has skyrocketed. ${ }^{44}$ OMSDs are simply, as the term suggests, state-party delegations composed of a single federal deputy. We acknowledge that it is possible that the real party "owners" are not necessarily federal deputies, and it is also possible that parties that elect more than one individual are still "owned" by one of them.

${ }^{45}$ The 27 states form the electoral districts for the PR elections, and $M$ ranges from 8 to 70 . 
${ }^{46}$ On patterns of vote dispersion under open-list PR, see Barry Ames, The Deadlock of

Democracy in Brazil (Ann Arbor: University of Michigan Press, 2001).

${ }^{47}$ We report additional, related measures of concentration in the online Appendix.

${ }^{48}$ Data on sources of campaign funding are taken from the Tribunal Superior Eleitoral (http://divulgacandcontas.tse.jus.br).

${ }^{49}$ Intended to translate companheiro or common-law husband.

${ }^{50}$ Caio Henrique Salgado, "Presidente do PR condenado por tortura," O Popular, 30 May 2013.

${ }^{51}$ Bruno Góes, “As armas e os gostos da bolsonarista Magda Mofatto, a deputada (oficialmente) mais rica do Congresso," Revista Época, 29 June 2018.

52 The national PL voted to direct its FEFC funding to incumbent deputies proportionally to their vote received in the previous election (2014). Since Mofatto had also been an OMSD in 2014, she received all of the PL funding for Chamber candidates in Goías. This transfer of 2 million BRL covered $84 \%$ of her campaign expenses (data from http://divulgacandcontas.tse.jus.br). ${ }^{53}$ The criterion here was for a OMSD to score higher on either HHI, or on the relative difference between first- and second-placed candidates, than the 75th percentile of the distribution of each indicator among lists that elected more than one candidate. These thresholds were 0.311 and $14.38 \%$, respectively.

${ }^{54}$ Very rarely, a personalistic vehicle is so successful that its vote total more than doubles the electoral quotient, and thus the party can no longer be classified as an OMSD. The most extreme coattail effect of this type occurred in São Paulo in 2002, when protest candidate Enéas Carneiro (PRONA) obtained 1,594,849 nominal votes - some 1,555,221 more than the second-placed PRONA finisher. Carneiro's surplus votes elected five other candidates. 
${ }^{55}$ Peter Siavelis, "Accommodating Informal Institutions and Chilean Democracy," in Gretchen Helmke and Stephen Levitsky, eds., Informal Institutions and Democracy: Lessons from Latin America (Baltimore: Johns Hopkins University Press, 2006), 33-55. 